\title{
Análise da Gestão Financeira nas Micro e Pequenas Empresas de Osasco
}

\author{
Analysis of Financial Management in Micro and Small \\ Enterprises Osasco
}

\author{
Recebido: 05/05/2015 - Aprovado: 05/06/2015 - Publicado: 27/06/2015 \\ Processo de Avaliação: Double Blind Review
}

\author{
Michele Caroline Lima Formenti \\ Graduada em Tecnologia em Gestão Financeira \\ Faculdade de Tecnologia de Osasco - Fatec Osasco ${ }^{1}$ \\ michelle_formenti@globo.com \\ Isabel Cristina Silva Martins \\ Graduada em Tecnologia em Gestão Financeira \\ Faculdade de Tecnologia de Osasco - Fatec Osasco \\ isabel.csmartins@ hotmail.com
}

\begin{abstract}
Resumo: Este estudo visa identificar qual o perfil de Gestão Financeira nas Microempresas (MEs) e nas Empresas de Pequeno Porte (EPPs) do município de Osasco. Para o desenvolvimento desta pesquisa primeiramente foi realizado um levantamento bibliográfico dos assuntos relacionados ao tema, tais como: Definição de ME e EPP, Lei Geral, Aspectos Tributários, Modelo Contábil (ITG 1000), Controles Financeiros. A segunda etapa constituiuse de pesquisa de campo em que foi elaborado um questionário para gestores das Microempresas (MEs) e Empresas de Pequeno Porte (EPPs) do município, a fim de identificar qual o modelo de Gestão Financeira adotado. O estudo revelou que mais de $80 \%$ das MEs e EPPs realizam algum tipo de controle financeiro, seja por meio de sistemas informatizados ou planilhas eletrônicas e que a maior dificuldade encontrada na Administração Financeira destas empresas são: elevada carga tributária, concorrência acirrada e falta de mão de obra qualificada.
\end{abstract}

Palavras-Chave: Microempresa e Empresa de Pequeno Porte; Controles Financeiros; Demonstrações Contábeis.

Abstract - This study aims to identify the profile of the Financial Management in the Small Business in Osasco city. For development of this research was first done a bibliographic survey of issues related to the topic, such as: Definition of Small Business, General Law, Tax Aspects, Accounting Model (ITG 1000), Financial Controls. The second stage consisted of field research in which a questionnaire was prepared for Small Business managers of the

\footnotetext{
${ }^{1}$ Autor para correspondência: Faculdade de Tecnologia do Estado de São Paulo, Rua Pedro Rissato, 30, Vila dos Remédios, Osasco - SP, Brasil - CEP 06296-220.
} 
municipality to identify the Financial Management model used. The study revealed that over $80 \%$ of Small Business perform some type of financial control, either by means of computer systems or electronic spreadsheets and that the greatest difficulty in Financial Management of these companies are: high taxes, tough competition and lack skilled labor.

Key Words: Small Business; Financial Controls; Financial Statements.

\section{1 - INTRODUÇÃO}

De acordo com o Serviço Brasileiro de Apoio às Micro e Pequenas Empresas (SEBRAE) existem atualmente no Brasil mais de 6,3 milhões de empresas, sendo que a cada ano são criados aproximadamente 1,2 milhões de empreendimentos formais. As Microempresas (MEs) e as Empresas de Pequeno Porte (EPPs) representam mais de 99\% destas empresas e são responsáveis por mais da metade dos empregos formais no País, sendo sua sobrevivência e desenvolvimento indispensáveis para a economia. Pesquisa publicada em 2013 pelo SEBRAE indica que 27\% das empresas paulistas fecham em seu primeiro ano de atividade e a falta de um modelo de Gestão Financeira eficaz é uma das principais causas da mortalidade destas empresas.

Em um cenário econômico cada vez mais globalizado e competitivo, administrar e garantir que a liquidez dos recursos em caixa seja suficiente para honrar com os compromissos assumidos pelas empresas é fundamental para sua continuidade. Para Teixeira (2012, p.335) "a ausência de controles adequados pode gerar descasamentos de caixa e utilização de fontes de recursos inadequadas, levando a empresa à insolvência e por consequência findar suas atividades".

Logo, a utilização de controles e demonstrativos é essencial na Gestão Financeira das empresas, visto que podem auxiliar o empresário na tomada de decisão e na adequação de questões como: ajuste no prazo de vendas e nos prazos de pagamentos aos fornecedores, gestão de custos, gestão de investimentos e redução ou aumento do estoque.

De acordo com dados do SEBRAE SP, 27\% das empresas paulistas fecham em seu primeiro ano de atividade e entre as principais causas que levam ao fechamento destas empresas pode-se destacar: falta de planejamento prévio e gestão deficiente do negócio.

Este trabalho possui o objetivo geral de analisar, por meio dos controles e demonstrativos adotados, o modelo de Gestão Financeira utilizado pelas MEs e EPPs do município de Osasco e apresenta a seguinte problematização: Quais são os Controles 
Financeiros utilizados pelas MEs e EPPs do município de Osasco? Quais são as Demonstrações Financeiras ou Contábeis (DFCs) elaboradas pelas MEs e EPPs do município de Osasco?

A escolha deste município para realização da pesquisa se deu em virtude da facilidade de acesso às empresas e ao fato de ser próximo da Capital e ter relações empresariais e comerciais muito fortes com a mesma.

\section{2 - REFERENCIAL TEÓRICO}

\section{1 - LEI GERAL DA MICRO E PEQUENA EMPRESA}

A continuidade e longevidade dos micro e pequenos negócios, além de ser essencial para o desenvolvimento econômico do país, é essencial para o desenvolvimento econômico e social do estado de São Paulo e do município de Osasco, visto que os mesmos representam mais de $90 \%$ das empresas do Estado de São Paulo e mais de $90 \%$ das empresas do município de Osasco.

\begin{tabular}{|c|c|c|c|c|c|c|c|c|c|c|c|c|}
\hline \multirow[b]{2}{*}{ Porte } & \multicolumn{4}{|c|}{ Brasil } & \multicolumn{4}{|c|}{ Estado de São Paulo } & \multicolumn{4}{|c|}{ Osasco } \\
\hline & \multicolumn{2}{|c|}{2007} & \multicolumn{2}{|c|}{2012} & \multicolumn{2}{|c|}{2007} & \multicolumn{2}{|c|}{2012} & \multicolumn{2}{|c|}{2007} & \multicolumn{2}{|c|}{2012} \\
\hline Total & 5.640 .870 & $100,00 \%$ & 6.405 .122 & $100,00 \%$ & 1.738 .538 & $100,00 \%$ & 1.959 .077 & $100,00 \%$ & 18.811 & $100,00 \%$ & 20.793 & $100,00 \%$ \\
\hline Microempresa & 5.313 .753 & $94,20 \%$ & 5.961 .402 & $93,07 \%$ & 1.634 .792 & $94,03 \%$ & 1.823 .861 & $93,10 \%$ & 17.554 & $93,32 \%$ & 19.187 & $92,28 \%$ \\
\hline Pequena empresa & 279.066 & $4,95 \%$ & 378.218 & $5,90 \%$ & 86.746 & $4,99 \%$ & 112.961 & $5,77 \%$ & 1.012 & $5,38 \%$ & 1.275 & $6,13 \%$ \\
\hline Média empresa & 31.403 & $0,56 \%$ & 41.890 & $0,65 \%$ & 11.069 & $0,64 \%$ & 14.058 & $0,72 \%$ & 156 & $0,83 \%$ & 216 & $1,04 \%$ \\
\hline Grande empresa & 16.648 & $0,30 \%$ & 23.612 & $0,37 \%$ & 5.931 & $0,34 \%$ & 8.197 & $0,42 \%$ & 89 & $0,47 \%$ & 115 & $0,55 \%$ \\
\hline
\end{tabular}

Tabela 1 - Número absoluto de estabelecimentos por porte Fonte: Adaptado DIEESE, 2014.

A Lei Geral da Micro e Pequena Empresa (MPE), instituída pela Lei Complementar $n^{\circ}$ 123, de 14 de dezembro de 2006, também conhecida como Estatuto Nacional das Microempresas e das Empresas de Pequeno Porte prevê o tratamento diferenciado e favorecido às MPEs em âmbito nacional, nos termos dos artigos 146, 170 e 179 da Constituição Federal. O principal objetivo desta lei é contribuir para o desenvolvimento e a aumento da competitividade das MEs e EPPs, auxiliando a geração de emprego, distribuição de renda, inclusão social, redução da informalidade e fortalecimento da economia. Para o SEBRAE, os principais benefícios previstos nesta lei incluem a redução da burocracia para a abertura, alteração e fechamento de empreendimentos; a desoneração tributária das receitas de 
exportação e substituição tributária; a redução da carga tributária e a simplificação dos processos de cálculo e recolhimento de impostos, através da criação Simples Nacional; o parcelamento de dívidas tributárias para adesão ao Simples Nacional; a preferência nas compras públicas; entre outros.

\section{2 - MODELO CONTÁBIL (ITG 1000)}

A ITG 1000 aprovada pela Resolução CFC N 1.418/2012 dispõe sobre modelos contábeis para MEs e EPPs. Para fins desta Interpretação, entende-se como "Microempresa e Empresa de Pequeno Porte", conforme o Art. $3^{\circ}$ da Lei Complementar 123 (BRASIL, 2006), a sociedade empresária, a sociedade simples, a empresa individual de responsabilidade limitada ou o empresário a que se refere o Art. 966 da Lei n. ${ }^{\circ}$ 10.406/02, que tenha auferido no ano calendário, no caso da $\mathrm{ME}$, receita bruta igual ou inferior a $\mathrm{R} \$ 360.000,00$ (trezentos e sessenta mil reais) e no caso da EPP, receita bruta superior a $\mathrm{R} \$ 360.000,00$ (trezentos e sessenta mil reais) e igual ou inferior e $\mathrm{R} \$ 3.600 .000,00$ (três milhões e seiscentos mil reais). A conformidade com a ITG 1000 não desobriga as MEs e EPPs de registrar os atos e fatos que possam vir a alterar seu patrimônio, de acordo com os princípios de Contabilidade Geral.

A ITG 1000 estabelece procedimentos para escrituração (de acordo com o regime de competência) das receitas, despesas e custos do período, conforme o disposto no item 10:

Os lançamentos contábeis no Livro Diário devem ser feitos diariamente. É permitido, contudo, que os lançamentos sejam feitos ao final de cada mês, desde que tenham como suporte os livros ou outros registros auxiliares escriturados em conformidade com a ITG 2000 - Escrituração Contábil, aprovada pela Resolução CFC n. ${ }^{\circ}$ 1.330/11.

Para casos não previstos nesta Interpretação, a entidade deve utilizar como referência a ITG 2000 - Escrituração Contábil e na NBC TG 1000 - Contabilidade para Pequenas e Médias Empresas (ITG 1000, 2012, item11).

Conforme Santos e Veiga (2014, p.28):

As empresas enquadradas como Microempresa ou Empresa de Pequeno Porte devem elaborar, pelo menos, ao final de cada exercício:

a. Balanço Patrimonial;

b. Demonstração do Resultado do Exercício;

c. Notas Explicativas. 
Os autores afirmam ainda que estas empresas devem elaborar periodicamente um plano de contas, ainda que simplificado e manter o registro do livro diário das operações contábeis.

É importante destacar que na ITG 1000, ANEXO 4, há um Plano de Contas Simplificado como modelo para ser adotado para as MEs e EPPs.

\section{3 - CONTROLES FINANCEIROS BÁSICOS}

De acordo com Teixeira (2012) os controles financeiros básicos são os que estão diretamente relacionados às atividades de escrituração das atividades financeiras da empresa $\mathrm{e}$ são fundamentais para Gestão Financeira da empresa e para elaboração dos indicadores financeiros por fornecerem uma base de dados confiável. Teixeira (2012) destaca os seguintes controles, que estão ligados à escrituração das atividades financeiras, e são essenciais: diário de caixa, controle bancário, controle de contas a pagar e receber, controle de vendas e controle de estoques.

A. Diário de Caixa: Para o SEBRAE/MG, o diário de caixa controla e registra todas as entradas e saídas de recursos financeiros do caixa da empresa, sendo que seu principal objetivo é verificar se não existem erros de registros ou desvios de recursos.

B. Controle Bancário: Ainda de acordo com o SEBRAE/MG, o controle bancário registra, diariamente, todas as movimentações bancárias da empresa. Seu objetivo principal é controlar os débitos, créditos e saldos existentes na conta da empresa.

C. Controle de Contas a Pagar: Na definição de Gitman (2012) a administração das contas a pagar consiste no controle, realizado pela empresa, do prazo transcorrido entre a compra de matérias-primas e a efetivação do pagamento ao fornecedor. Este controle, se utilizado corretamente, auxilia o administrador/empresário a estabelecer as prioridades de pagamento, caso a empresa enfrente dificuldades financeiras, bem como permite ao mesmo avaliar e controlar o montante dos compromissos vencidos.

D. Controle de Contas a Receber: Segundo Neto e Silva (2009) as contas a receber dizem respeito aos créditos concedidos aos clientes, mediante uma promessa de 
pagamento futuro. Sua finalidade é controlar os valores a receber, provenientes das vendas a prazo, bem como fornecer informações pertinentes ao total de valores a receber por cliente, entre outras.

E. Controle de Vendas: Para o SEBRAE/MG a principal finalidade do controle de vendas é acompanhar o volume de vendas diárias e o total de vendas acumuladas a cada mês. É uma ferramenta importante, pois ajuda o empresário a identificar se as metas e a projeção de vendas pré-estabelecidas estão sendo alcançadas.

F. Controle de Estoques: O controle de estoque auxilia no planejamento e decisões de compra, pois permite a identificação dos itens com maior e menor giro (saída), auxiliando o empresário ou administrador financeiro a direcionar os recursos para a compra dos produtos que realmente são necessários. De acordo com o SEBRAE/MG, este controle também permite: assegurar o suprimento necessário para atender à demanda dos clientes, manter o custo de armazenamento o mais baixo possível, auxiliar na política de preços de vendas, estimar custos das mercadorias vendidas, entre outros.

\section{3 - METODOLOGIA}

Para desenvolver este trabalho foi realizada uma pesquisa exploratória com o objetivo de realizar o levantamento bibliográfico dos assuntos relacionados ao tema, incluindo a legislação pertinente e um estudo de caso com levantamento de dados em campo. A natureza da pesquisa de campo é quantitativa, pois foram analisados os dados das empresas estudadas, utilizados para determinar o modelo de Gestão Financeira utilizado pelas empresas representadas por esta amostra.

Para a pesquisa de campo foi desenvolvido um questionário com 20 questões fechadas para aplicação aos empresários e ou responsáveis pela Gestão Financeira de MEs e EPPS no município de Osasco. O objetivo era coletar dados a fim de identificar quais os controles financeiros e quais DFCs eram elaboradas, bem como identificar outras variáveis, tais como: nível de instrução do responsável pela gestão, regime tributário adotado, setor de atuação e outros. O questionário foi aplicado em duas empresas com a finalidade de identificar 
possíveis falhas e definir o formato final. Após a realização das devidas correções, o questionário final foi enviado a 150 empresas, sendo que 21 retornaram, por isso, pode-se afirmar que foi realizada uma pesquisa laboratorial com uma amostra por conveniência, porém não significativa.

\section{4 - PESQUISA}

Realizou-se a aplicação de um questionário, elaborado pelas autoras, com 20 questões fechadas aplicadas em uma amostra definida como teste, por conveniência e não significativa, de MEs e EPPs localizadas no município de Osasco. Trata-se, portanto, de uma pesquisa laboratorial. O questionário foi enviado por e-mail para 150 empresas, sendo que foi realizado contato telefônico com 30 destas empresas e entrevista com 3 empresários. No final houve retorno de 21 empresas, a limitação do número de questionários respondidos se deve às dificuldades encontradas para conseguir contato direto com os empresários e ou gestores da área financeira em virtude da falta de tempo/disponibilidade dos mesmos.

\section{1 - PERFIL DAS EMPRESAS ANALISADAS}

Conforme os dados apresentados na Tabela 2 e no Gráfico 1, as empresas analisadas são de 12 bairros diferentes, considerando que o município de Osasco possui 60 bairros. Assim, pode-se afirmar que a amostra analisada representa $20 \%$ do universo da pesquisa. Das 21 empresas analisadas, mais de 60 \% são do setor Comercial e de Prestação de Serviços.

\begin{tabular}{ccc}
\hline Setor & Quantidade & Percentual \\
\hline Comércio & 6 & $28,57 \%$ \\
\hline $\begin{array}{c}\text { Comércio e Prestação de } \\
\text { Serviços }\end{array}$ & 2 & $9,52 \%$ \\
\hline Indústria & 8 & $38,10 \%$ \\
\hline Prestação de Serviços & 5 & $23,81 \%$ \\
\hline Total geral & $\mathbf{2 1}$ & $\mathbf{1 0 0 \%}$
\end{tabular}

Tabela 2 - Setor de Atuação.

Fonte: Dados da Pesquisa.

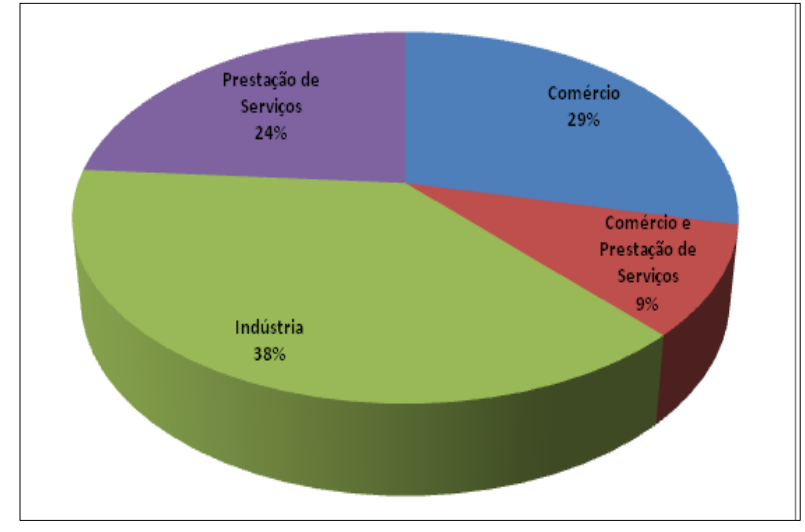

Gráfico 1 - Setor de Atuação. Fonte: Dados da Pesquisa. 
De acordo com os dados coletados, 47,62\% dos responsáveis pela Gestão Financeira das empresas possuem Ensino Superior Completo, conforme demonstram a Tabela 3 e o Gráfico 2.

\begin{tabular}{|c|c|c|c|}
\hline $\begin{array}{c}\text { Escolaridade do } \\
\text { Responsável pela Área } \\
\text { Financeira }\end{array}$ & Setor & Quantidade & Percentual \\
\hline \multirow{3}{*}{$\begin{array}{l}\text { Ensino Fundamental } \\
\text { Incompleto }\end{array}$} & Comércio & 1 & $4,76 \%$ \\
\hline & $\begin{array}{c}\text { Comércio e Prestação de } \\
\text { Serviços }\end{array}$ & 1 & $4,76 \%$ \\
\hline & Total & 2 & $9,52 \%$ \\
\hline \multirow{3}{*}{ Ensino Médio Completo } & Comércio & 1 & $4,76 \%$ \\
\hline & Indústria & 2 & $9,52 \%$ \\
\hline & Total & 3 & $14,29 \%$ \\
\hline \multirow{5}{*}{ Ensino Superior Completo } & Comércio & 1 & $4,76 \%$ \\
\hline & $\begin{array}{c}\text { Comércio e Prestação de } \\
\text { Serviços }\end{array}$ & 1 & $4,76 \%$ \\
\hline & Indústria & 5 & $23,81 \%$ \\
\hline & Prestação de Serviços & 3 & $14,29 \%$ \\
\hline & Total & 10 & $47,62 \%$ \\
\hline \multirow{3}{*}{ Ensino Superior Incompleto } & Comércio & 2 & $9,52 \%$ \\
\hline & Indústria & 1 & $4,76 \%$ \\
\hline & Total & 3 & $14,29 \%$ \\
\hline \multirow{3}{*}{$\begin{array}{l}\text { Pós-graduação, MBA, } \\
\text { Mestrado ou Doutorado }\end{array}$} & Comércio & 1 & $4,76 \%$ \\
\hline & Prestação de Serviços & 2 & $9,52 \%$ \\
\hline & Total & 3 & $14,29 \%$ \\
\hline
\end{tabular}

Tabela 3 - Escolaridade do Gestor Financeiro por Setor de Atuação. Fonte: Dados da Pesquisa.

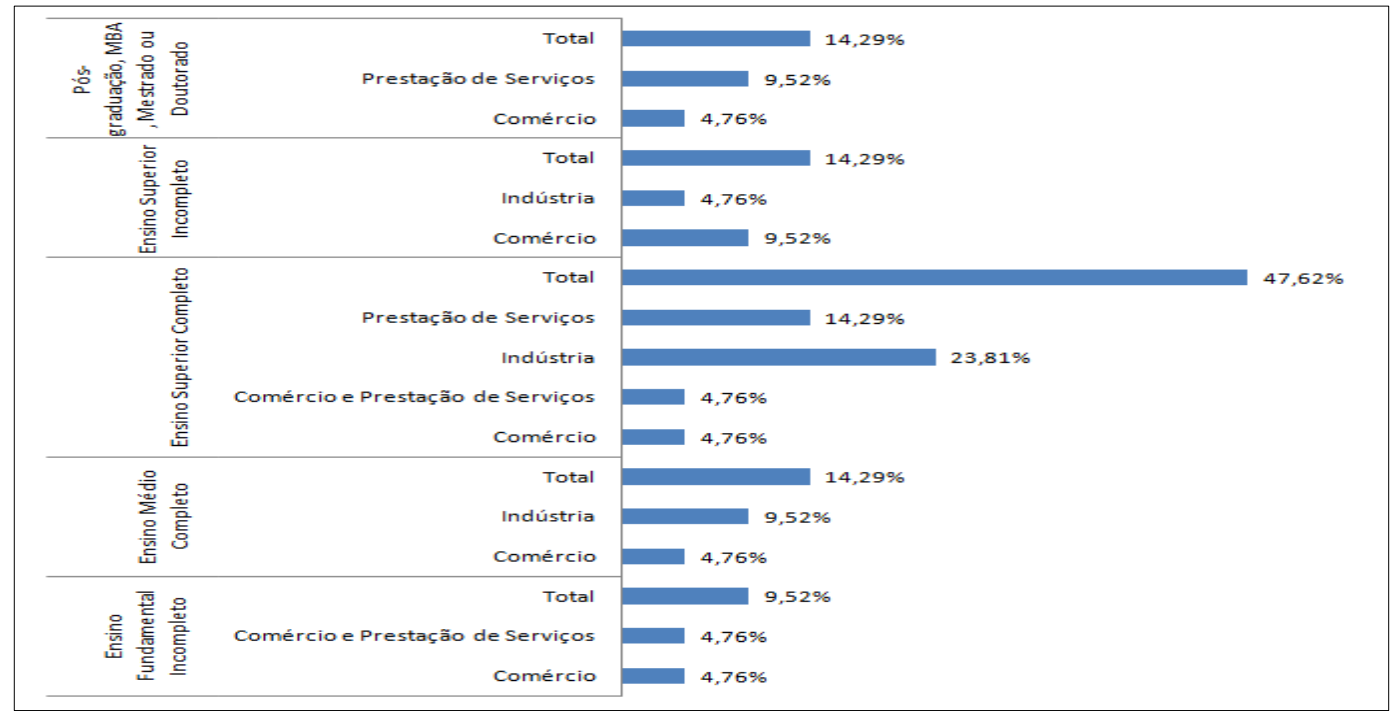

Gráfico 2 - Escolaridade do Gestor Financeiro por Setor de Atuação.

Fonte: Dados da Pesquisa. 
Em relação ao tipo de empresa (natureza jurídica), mais de 50\% das empresas foram constituídas como Sociedade Limitada e quase $29 \%$ foram constituídas como Empresário Individual.

Utilizando a tabela de classificação do SEBRAE, que define o porte da empresa de acordo com seu número de funcionários, pode-se afirmar que da amostra analisada, 57,14\% das empresas são Microempresas e 42,86\% são Empresas de Pequeno Porte, sendo que 61,9\% destas empresas foram abertas há mais de 6 anos.

\section{2 - PERFIL DA GESTÃO FINANCEIRA}

Com base nos dados coletados, pode-se definir o perfil da Gestão Financeira realizada nas Micro e Pequenas Empresas do município de Osasco.

A. Plano de Negócio: A Tabela 4 e o Gráfico 3 mostram que mais de $47 \%$ das empresas analisadas não tiveram embasamento em um Plano de Negócios antes de sua abertura.

\begin{tabular}{lcc}
\hline Plano de Negócio & Quantidade & Percentual \\
\hline Não & 10 & $47,62 \%$ \\
\hline Não sabe responder & 3 & $14,29 \%$ \\
\hline Sim & 8 & $38,10 \%$ \\
\hline Total geral & $\mathbf{2 1}$ & $\mathbf{1 0 0 \%}$
\end{tabular}

Tabela 4 - Plano de Negócios. Fonte: Dados da Pesquisa.

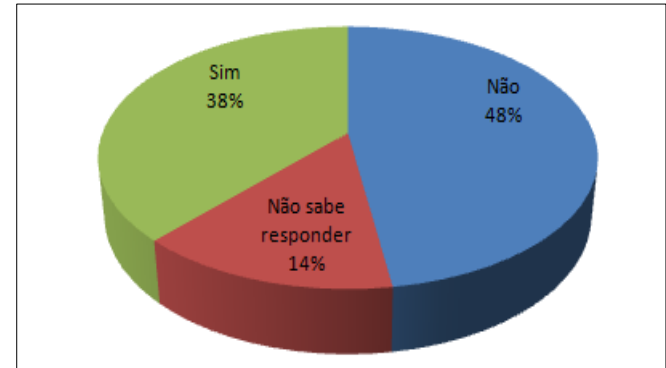

Gráfico 3 - Plano de Negócios. Fonte: Dados da pesquisa.

B. Importância dos Controles Financeiros para Gestão da Empresa: Mais de $80 \%$ das empresas analisadas afirmaram que acreditam que a realização de Controles Financeiros é fundamental para a gestão da empresa, conforme demonstram a Tabela 5 e o Gráfico 4.

\begin{tabular}{lcc}
$\begin{array}{l}\text { Controles financeiros são importantes } \\
\text { para Gestão da sua Empresa? }\end{array}$ & Quantidade & Percentual \\
\hline Concordo plenamente & 18 & $85,71 \%$ \\
\hline Concordo parcialmente & 3 & $14,29 \%$ \\
\hline & $\mathbf{2 1}$ & $\mathbf{1 0 0 , 0 0 \%}$ \\
Total geral & \\
Tabela 5 - Importância dos Controles Financeiros. & \\
Fonte: Dados da Pesquisa.
\end{tabular}

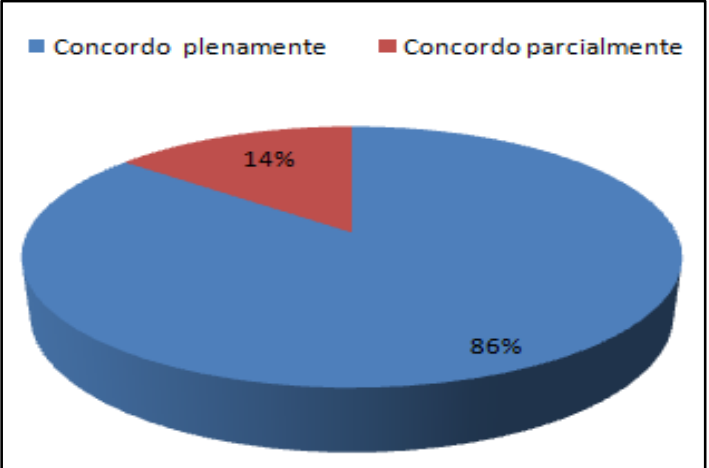


Gráfico 4 - Importância dos Controles Financeiros.

Fonte: Dados da Pesquisa.

C. laboração dos Controles Financeiros: De acordo com os dados demonstrados na Tabela 6 e no Gráfico 5, nota-se que há uma pequena diferença percentual (aproximadamente $10 \%$ ) entre as empresas que elaboram controles financeiros por meio de planilhas eletrônicas e as empresas que elaboram controles financeiros por meio de algum sistema informatizado. É importante ressaltar que independente do meio utilizado, mais de $90 \%$ das empresas elaboram algum tipo de controle financeiro.

\begin{tabular}{lcc}
\hline Elaboração Controles Financeiros & Quantidade & Percentual \\
\hline Planilhas em Excel & 11 & $52,38 \%$ \\
\hline Sistemas/Programas & 9 & $42,86 \%$ \\
\hline Não controla & 1 & $4,76 \%$ \\
\hline Total geral & $\mathbf{2 1}$ & $\mathbf{1 0 0 , 0 0 \%}$ \\
Tabela 6 - Elaboração de Controles Financeiros. \\
Fonte: Dados da Pesquisa.
\end{tabular}

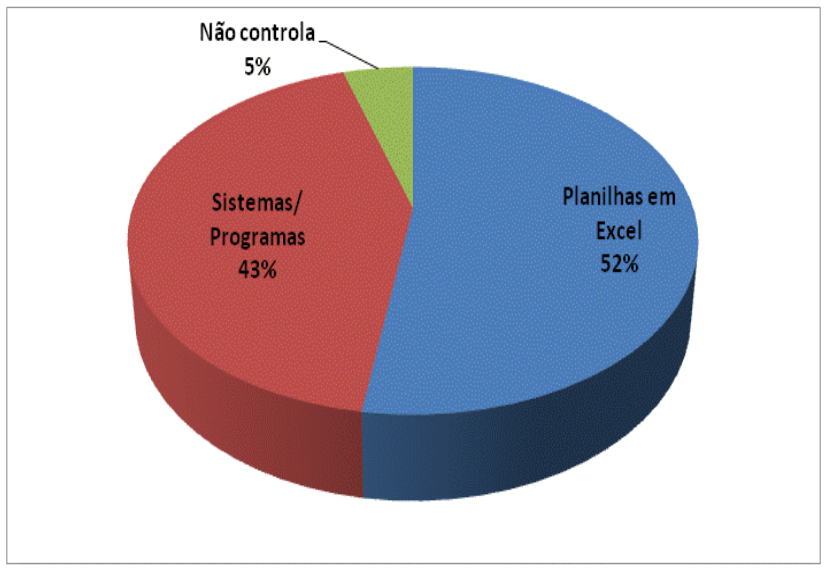

Gráfico 5 - Elaboração de Controles Financeiros.

Fonte: Dados da pesquisa.

D. Demonstrações Contábeis: Conforme mostram a Tabela 7 e o Gráfico 6, mais de 50\% das empresas elaboram as Demonstrações Financeiras ou Contábeis (DFCs) que são exigidas pela ITG 1000, entretanto, 5\% das empresas não elaboram nenhum Demonstrativo Contábil e 10\% das empresas não elaboram as DFCs obrigatórias. 


\begin{tabular}{l|c|c}
\hline Descrição & Frequência & Percentual \\
\hline Balanço Patrimonial & 15 & $71 \%$ \\
\hline DRE (Demonstrativo de Resultados) & 12 & $57 \%$ \\
\hline Notas Explicativas & 5 & $24 \%$ \\
\hline Não são elaboradas demonstrações contábeis/financeiras & 1 & $5 \%$ \\
\hline Outros - Planilha de Custo & 1 & $5 \%$ \\
\hline Outros - Relatórios Gerenciais & 1 & $5 \%$ \\
\hline
\end{tabular}

Tabela 7 - Demonstrações Contábeis.

Fonte: Dados da Pesquisa.

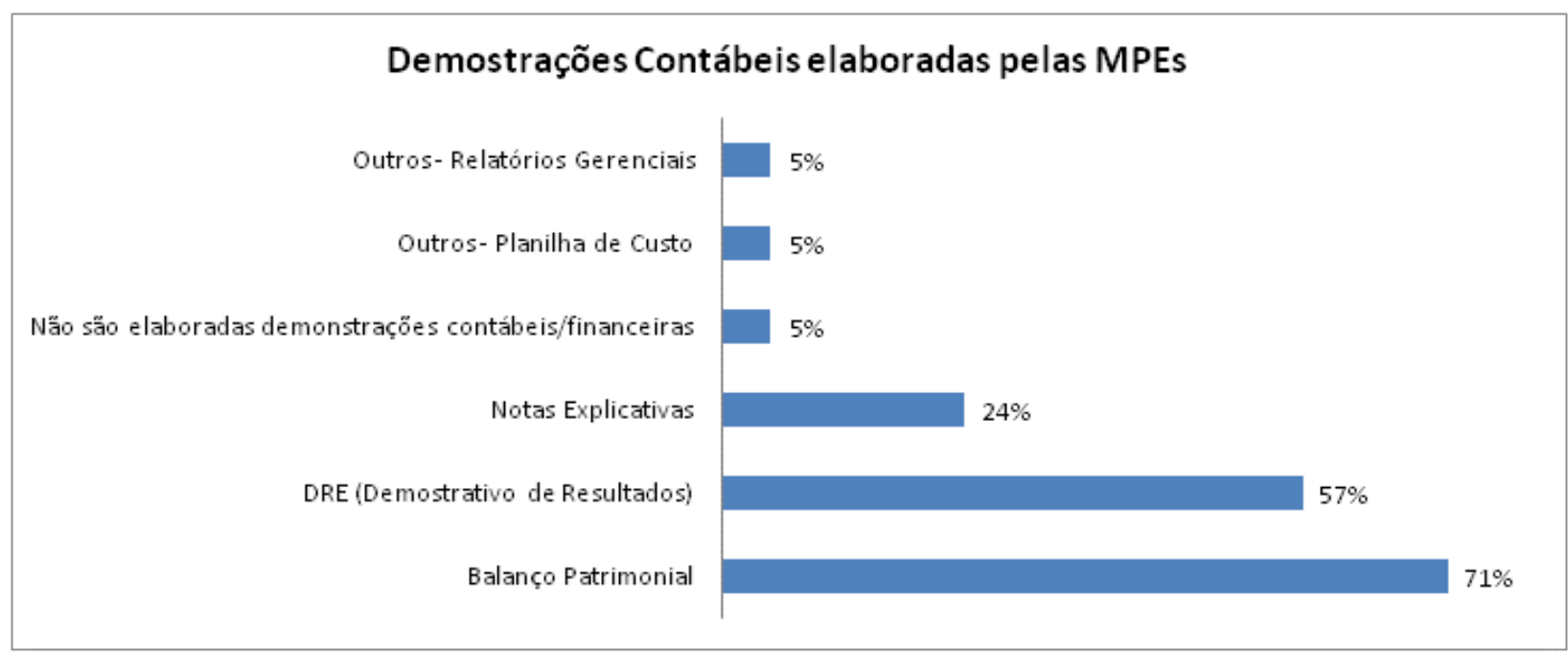

Gráfico 6 - Demonstrações Contábeis.

Fonte: Dados da Pesquisa.

E. Utilização das Demonstrações Contábeis: A Tabela 8 e o Gráfico 7 mostram que $81 \%$ das empresas analisadas afirmam utilizar os resultados das DFCs para avaliar se estão tendo lucro ou prejuízo, $62 \%$ afirmam que utilizam os resultados para tomada de decisões em relação ao direcionamento do negócio e $52 \%$ das empresas analisadas afirmaram que utilizam as demonstrações contábeis como uma ferramenta de apoio na definição das estratégias de vendas.

\begin{tabular}{l|c|c}
\hline Descrição & Frequência & Percentual \\
\hline Avaliar se a empresa está tendo lucro ou prejuízo & 17 & $81 \%$ \\
\hline Tomada decisão & 13 & $62 \%$ \\
\hline Definir estratégias de vendas & 11 & $52 \%$ \\
\hline Definir políticas de compras & 6 & $29 \%$ \\
\hline Solicitar financiamento bancário & 6 & $29 \%$ \\
\hline Não utiliza os resultados & 2 & $10 \%$ \\
\hline
\end{tabular}

Tabela 8 - Utilização das Demonstrações Contábeis.

Fonte: Dados da Pesquisa. 


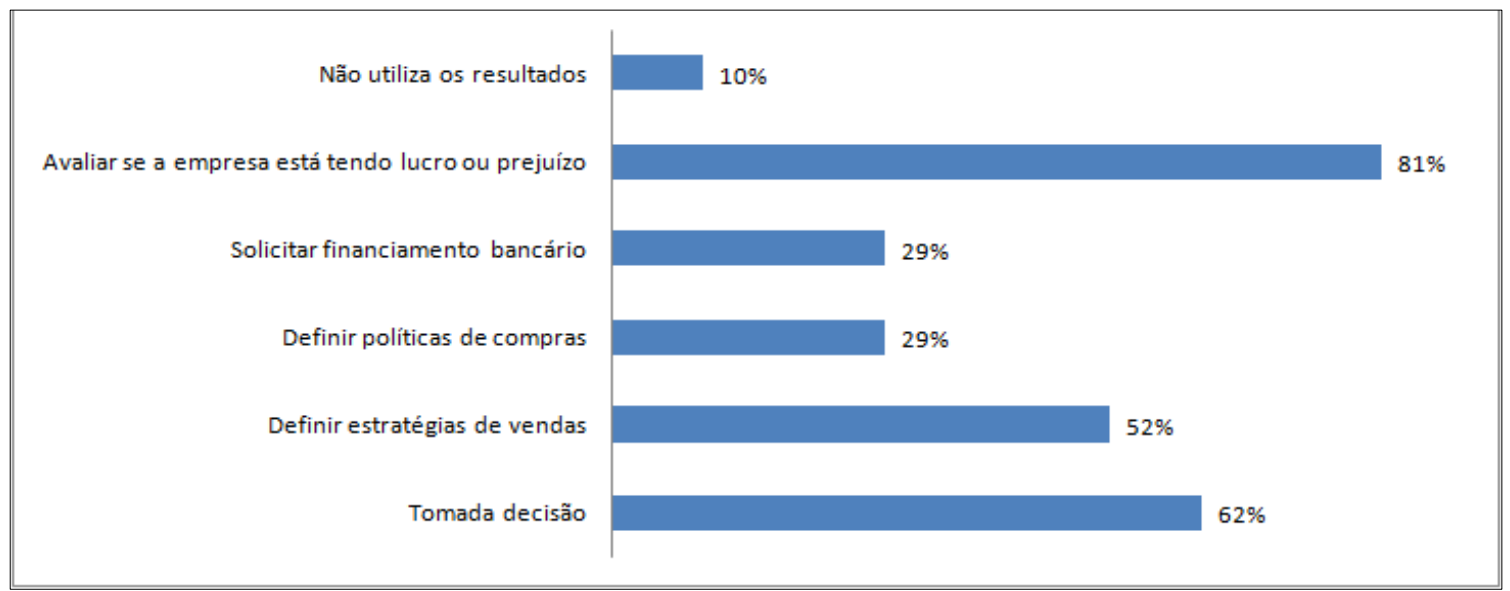

Gráfico 7 - Utilização das Demonstrações Contábeis.

Fonte: Dados da Pesquisa.

F. Avaliação da Situação Financeira: De acordo com os dados mostrados na Tabela 9 e no Gráfico 8, mais de $60 \%$ das empresas utilizam os seguintes controles financeiros para avaliar/controlar as finanças da empresa: Acompanhamento do Fluxo de Caixa, Acompanhamento Bancário e Acompanhamento das Contas a Pagar e a Receber.

\begin{tabular}{c|c|c}
\hline Descrição & Frequência & Percentual \\
\hline Acompanhamento do Fluxo de Caixa & 19 & $90 \%$ \\
\hline Acompanhamento Bancário & 13 & $62 \%$ \\
\hline Acompanhamento das Contas a Pagar & 15 & $71 \%$ \\
\hline Acompanhamento das Contas a Receber & 13 & $62 \%$ \\
\hline Controle do Estoque & 8 & $38 \%$ \\
\hline Controle das Vendas & 8 & $38 \%$ \\
\hline $\begin{array}{c}\text { Avaliação dos Índices Econômicos- Financeiros } \\
\text { (liquidez, endividamento, etc.) }\end{array}$ & 6 & $29 \%$ \\
\hline Não realiza nenhum Controle Financeiro & 1 & $5 \%$ \\
\hline
\end{tabular}

Tabela 9 - Avaliação da Situação Financeira.

Fonte: Dados da Pesquisa.

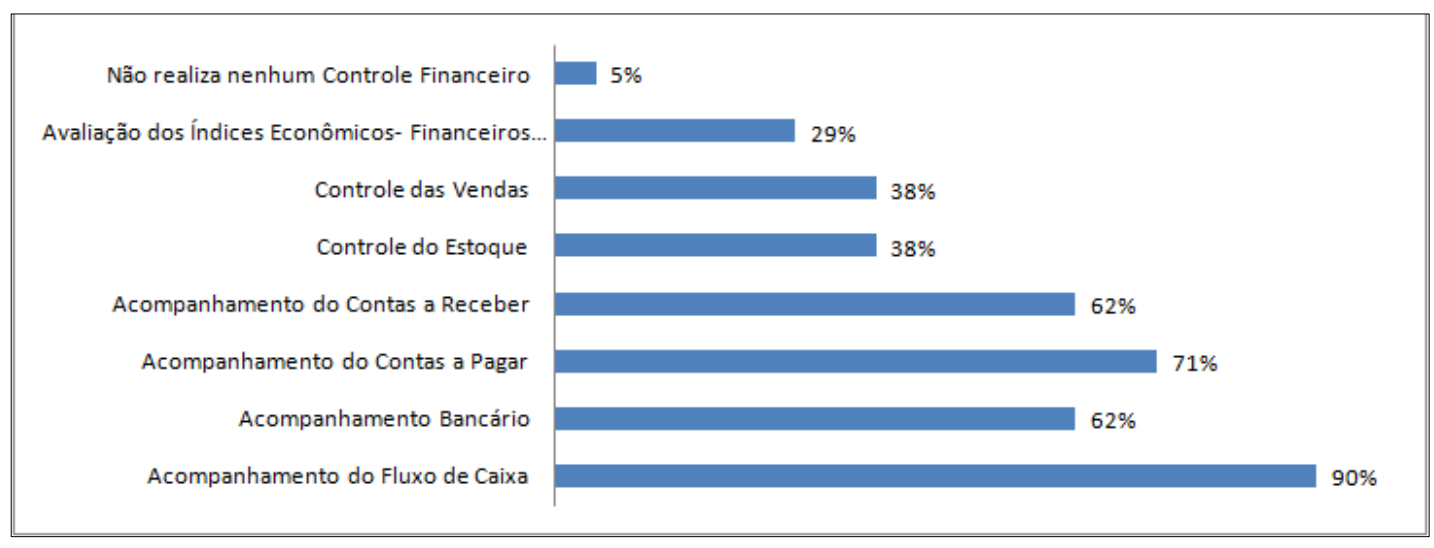


Gráfico 8 - Avaliação da Situação Financeira.

Fonte: Dados da Pesquisa.

G. Importância dos Controles Financeiros: De acordo com os dados coletados, os controles financeiros que as MEs e EPPs consideram muito importantes são: Fluxo de Caixa (86\%), Vendas (71\%), Contas a Pagar (67\%), Bancário (57\%) e Contas a Receber (52\%). Para $10 \%$ das empresas analisadas a Demonstração de Resultado do Exercício é um controle pouco importante, bem como $14 \%$ das empresas analisadas consideram o Balanço Patrimonial e o Acompanhamento Bancário pouco importantes, conforme demonstram a Tabela 10 e o Gráfico 9.

\begin{tabular}{|c|c|c|c|c|c|c|c|c|}
\hline & \multicolumn{2}{|c|}{$\begin{array}{c}\text { Muito } \\
\text { Importante }\end{array}$} & \multicolumn{2}{|c|}{ Importante } & \multicolumn{2}{|c|}{$\begin{array}{c}\text { Pouco } \\
\text { Importante }\end{array}$} & \multicolumn{2}{|c|}{ Desnecessário } \\
\hline & Qtde & $\%$ & Qtde & $\%$ & Qtde & $\%$ & Qtde & $\%$ \\
\hline Fluxo de Caixa & 18 & $86 \%$ & 1 & $5 \%$ & 1 & $5 \%$ & 1 & $5 \%$ \\
\hline Contas a pagar & 14 & $67 \%$ & 7 & $33 \%$ & 0 & $0 \%$ & 0 & $0 \%$ \\
\hline Contas a receber & 11 & $52 \%$ & 9 & $43 \%$ & 0 & $0 \%$ & 1 & $5 \%$ \\
\hline Estoque & 9 & $43 \%$ & 5 & $24 \%$ & 3 & $14 \%$ & 4 & $19 \%$ \\
\hline Vendas & 15 & $71 \%$ & 5 & $24 \%$ & 0 & $0 \%$ & 1 & $5 \%$ \\
\hline Bancário & 12 & $57 \%$ & 6 & $29 \%$ & 3 & $14 \%$ & 0 & $0 \%$ \\
\hline Balanço Patrimonial & 6 & $29 \%$ & 11 & $52 \%$ & 3 & $14 \%$ & 1 & $5 \%$ \\
\hline DRE & 9 & $43 \%$ & 9 & $43 \%$ & 2 & $10 \%$ & 1 & $5 \%$ \\
\hline
\end{tabular}

Tabela 10 - Importância dos Controles Financeiros.

Fonte: Dados da Pesquisa.

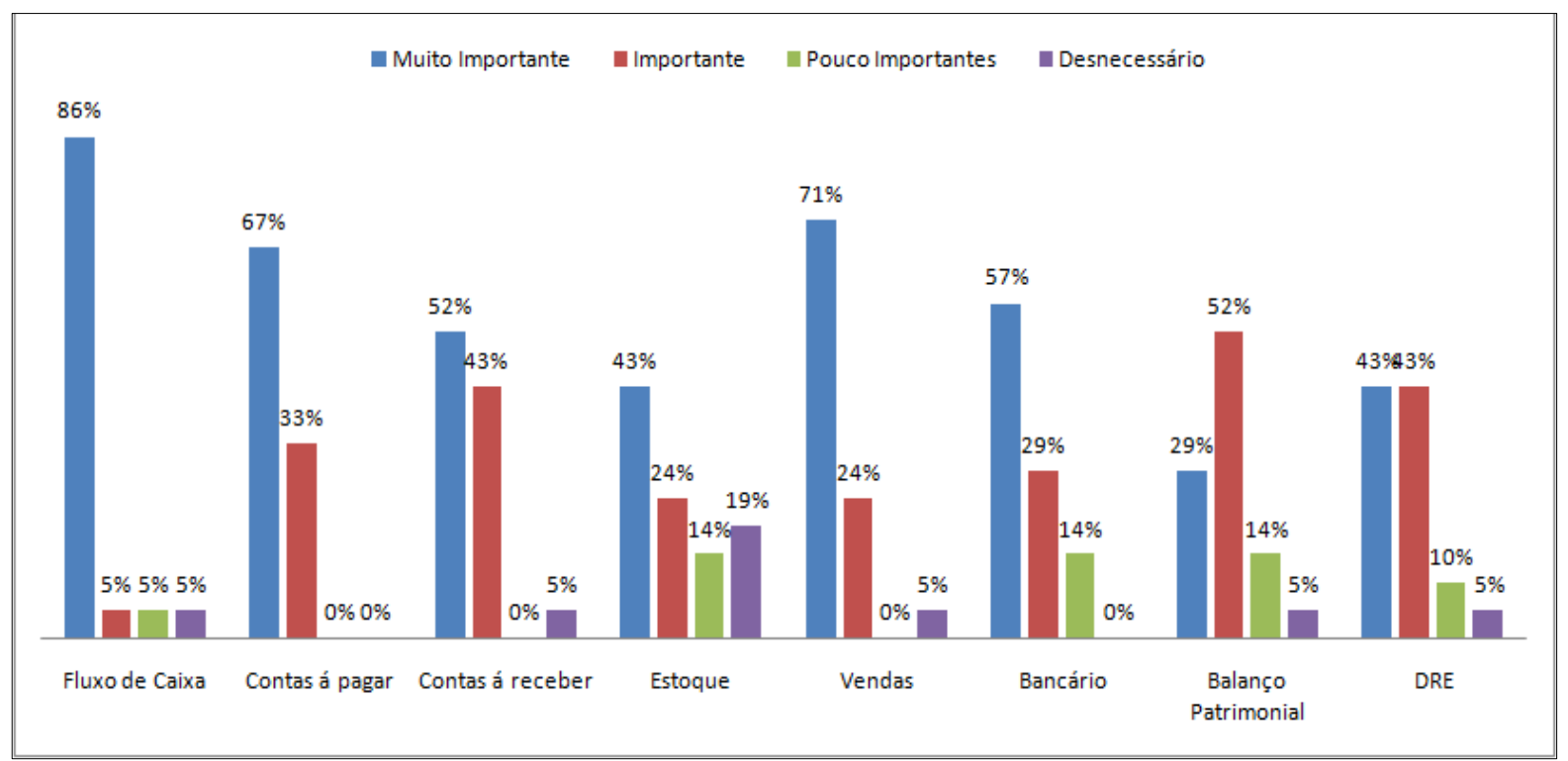


Gráfico 9 - Importância dos Controles Financeiros.

Fonte: Dados da Pesquisa.

H. Áreas consideradas difíceis de administrar: Os dados da Tabela 11 e do Gráfico 10 mostram as áreas que os empresários e/ou responsáveis pela Gestão Financeira têm mais dificuldade de administrar são: Fiscal e de Vendas; enquanto a Tabela 12 e o Gráfico 11 demonstram que as maiores causas apontadas para estas dificuldades são: falta de sistema adequado ao negócio, falta de mão de obra qualificada e falta de apoio do setor público.

\begin{tabular}{l|c|c}
\hline Áreas & Frequência & Percentual \\
\hline Fiscal & 12 & $57 \%$ \\
\hline Estoques & 8 & $38 \%$ \\
\hline Vendas & 4 & $19 \%$ \\
\hline Contas a Receber & 2 & $10 \%$ \\
\hline Contas a Pagar & 1 & $5 \%$ \\
\hline Fluxo de Caixa & 1 & $5 \%$ \\
\hline Outros - Nenhuma & 1 & $5 \%$ \\
\hline
\end{tabular}

Tabela 11 - Áreas Difíceis de Administrar Fonte: Dados da Pesquisa

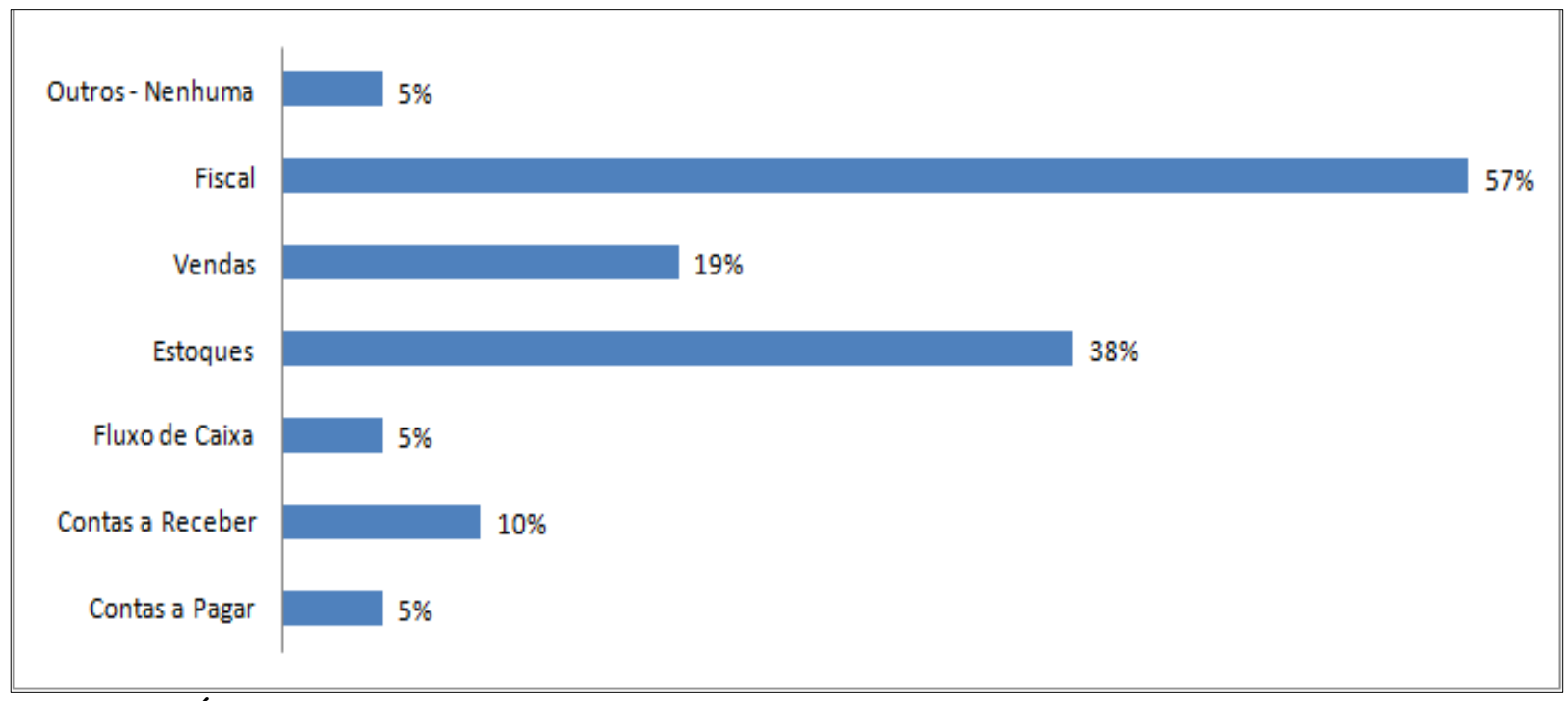

Gráfico 10 - Áreas Difíceis de Administrar.

Fonte: Dados da Pesquisa. 


\begin{tabular}{l|c|c}
\hline Causas que dificultam administração & Frequência & Percentual \\
\hline Falta de sistema/modelo de gestão adequado & 11 & $52 \%$ \\
\hline Falta de mão de obra qualificada & 7 & $33 \%$ \\
\hline Falta de apoio público & 5 & $24 \%$ \\
\hline Pouca experiência & 4 & $19 \%$ \\
\hline Falta de recursos financeiros (dinheiro/crédito) & 3 & $14 \%$ \\
\hline Outros - Nenhuma & 1 & $5 \%$ \\
\hline
\end{tabular}

Tabela 12 - Causas que Dificultam a Administração destas Áreas. Fonte: Dados da Pesquisa.

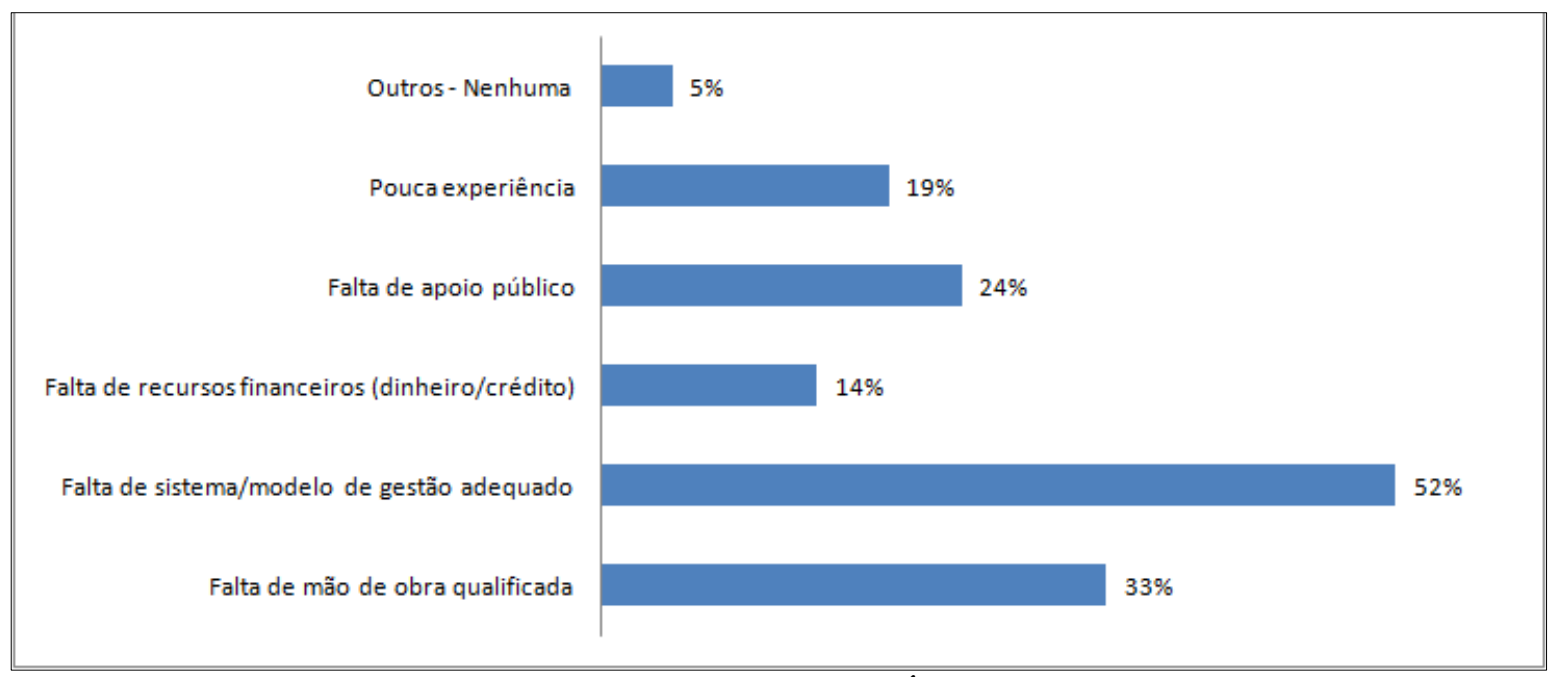

Gráfico 11 - Causas que Dificultam a Administração destas Áreas. Fonte: Dados da Pesquisa.

I. Definição Preço de Venda: De acordo com os dados mostrados na Tabela 13 e no Gráfico 12, os preços de venda de $62 \%$ das empresas analisadas são definidos com base no custo, $48 \%$ são definidos com base em uma margem de lucro pré-definida e $43 \%$ são definidos com base no setor de atuação. 


\begin{tabular}{l|c|c}
\hline Descrição & Frequência & $\%$ \\
\hline Com base no custo & 13 & $62 \%$ \\
\hline Com base em uma margem de lucro pré-definida & 10 & $48 \%$ \\
\hline Com base no mercado de atuação & 9 & $43 \%$ \\
\hline
\end{tabular}

Tabela 13 - Definição do Preço de Venda.

Fonte: Dados da Pesquisa.

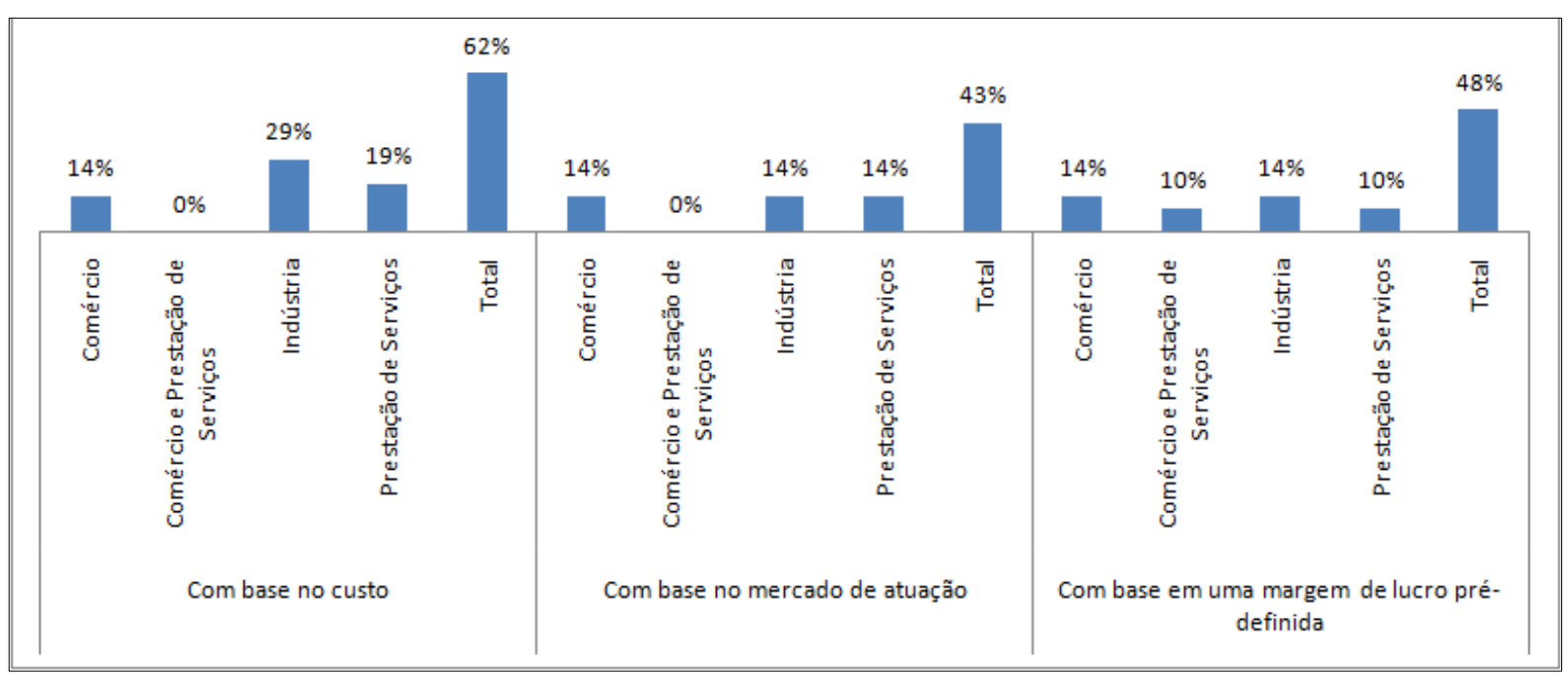

Gráfico 12 - Definição do Preço de Venda.

Fonte: Dados da Pesquisa.

J. Outras Informações: A Tabela 14 e o Gráfico 13 mostram que 95\% das empresas afirmaram que possuem cadastro de clientes, $81 \%$ possuem cadastro de fornecedores e controlam os custos das mercadorias/serviços vendidos, 33\% afirmam que, antes de uma venda, não consultam as informações dos clientes junto aos órgãos de proteção ao crédito e não realizam uma análise para verificar se é viável adquirir alguma máquina e/ou equipamento. 


\begin{tabular}{l|c|c|c|c}
\hline \multicolumn{1}{c|}{ Sobre sua empresa é possível afirmar que: } & Sim & \% & Não & \% \\
\hline Possui cadastro de clientes & 20 & $95 \%$ & 1 & $5 \%$ \\
\hline Possui cadastro de fornecedores & 17 & $81 \%$ & 4 & $19 \%$ \\
\hline $\begin{array}{l}\text { Antes de uma venda consulta as informações dos clientes junto aos órgãos } \\
\text { de proteção ao crédito (SERASA, SPC)? }\end{array}$ & 14 & $67 \%$ & 7 & $33 \%$ \\
\hline $\begin{array}{l}\text { Antes de realizar uma compra de ativo fixo (maquinas, equipamentos e } \\
\text { outros) é feita uma análise para verificar o prazo para recuperação do } \\
\text { valor (R\$) investido? }\end{array}$ & 14 & $67 \%$ & 7 & $33 \%$ \\
\hline $\begin{array}{l}\text { A empresa possui controle dos custos dos produtos, mercadorias ou } \\
\text { serviços ofertados? }\end{array}$ & 17 & $81 \%$ & 4 & $19 \%$ \\
\hline
\end{tabular}

Tabela 14 - Outras Informações.

Fonte: Dados da Pesquisa.

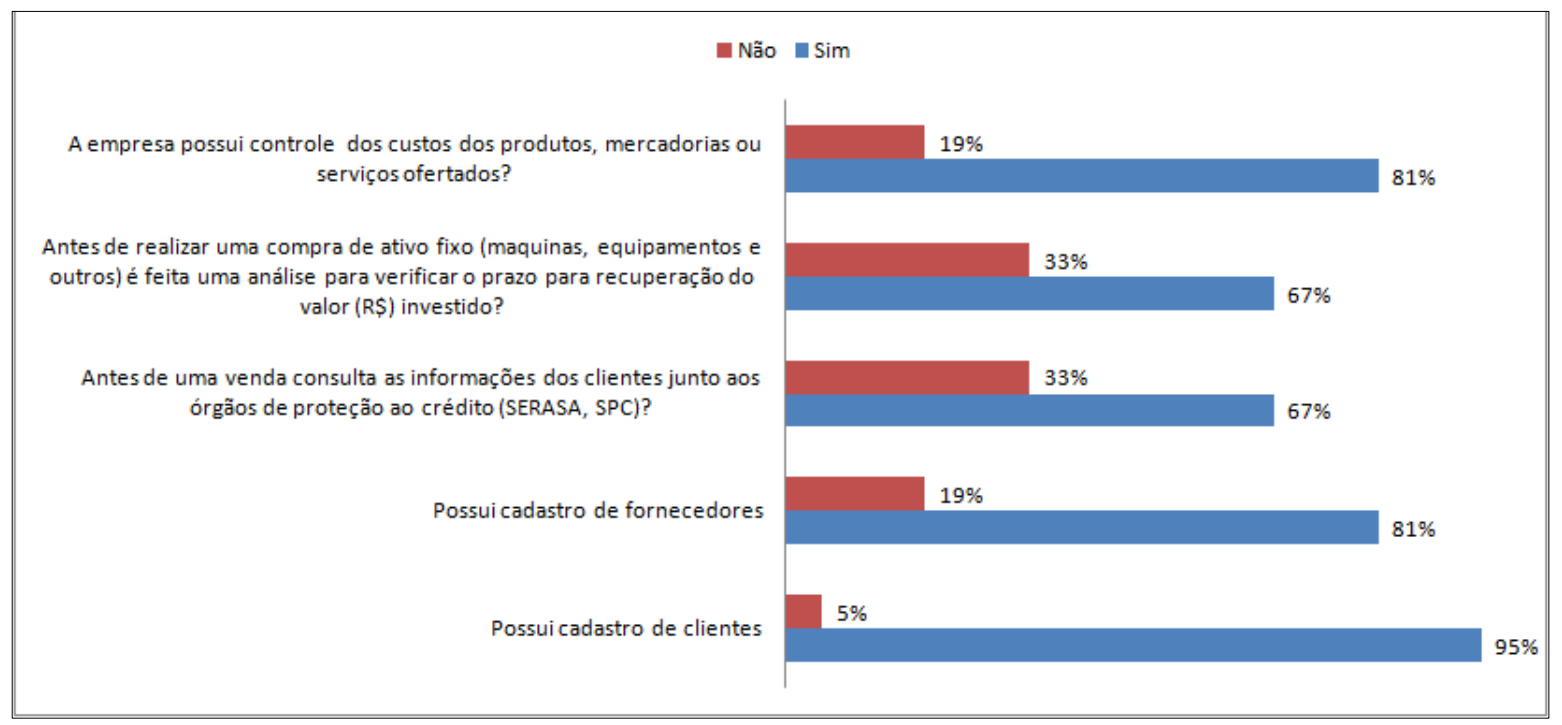

Gráfico 13 - Outras Informações.

Fonte: Dados da Pesquisa.

K. Responsáveis pela administração das áreas: Quanto à Administração Financeira, em 95\% dos casos analisados, é elaborada pela própria empresa, já a Administração Contábil e Fiscal, em mais de $65 \%$ da amostra, é realizada por uma contabilidade terceirizada, conforme dados da Tabela 15 e do Gráfico 14. 


\begin{tabular}{c|c|c|c|c|c|c|c|c}
\hline & $\begin{array}{c}\text { Própria } \\
\text { empresa }\end{array}$ & $\%$ & Contabilidade & $\%$ & Terceiros & $\%$ & $\begin{array}{c}\text { Não é } \\
\text { realizada }\end{array}$ & $\%$ \\
\hline $\begin{array}{c}\text { A administração } \\
\text { financeira é realizada }\end{array}$ & 20 & $95 \%$ & 0 & $0 \%$ & 0 & $0 \%$ & 1 & $5 \%$ \\
\hline $\begin{array}{c}\text { A administração } \\
\text { contábil é realizada }\end{array}$ & 4 & $19 \%$ & 16 & $76 \%$ & 0 & $0 \%$ & 1 & $5 \%$ \\
\hline $\begin{array}{c}\text { A administração fiscal } \\
\text { é realizada }\end{array}$ & 5 & $24 \%$ & 14 & $67 \%$ & 1 & $5 \%$ & 1 & $5 \%$ \\
\hline
\end{tabular}

Tabela 15 - Gestão Contábil, Fiscal e Financeira.

Fonte: Dados da Pesquisa.

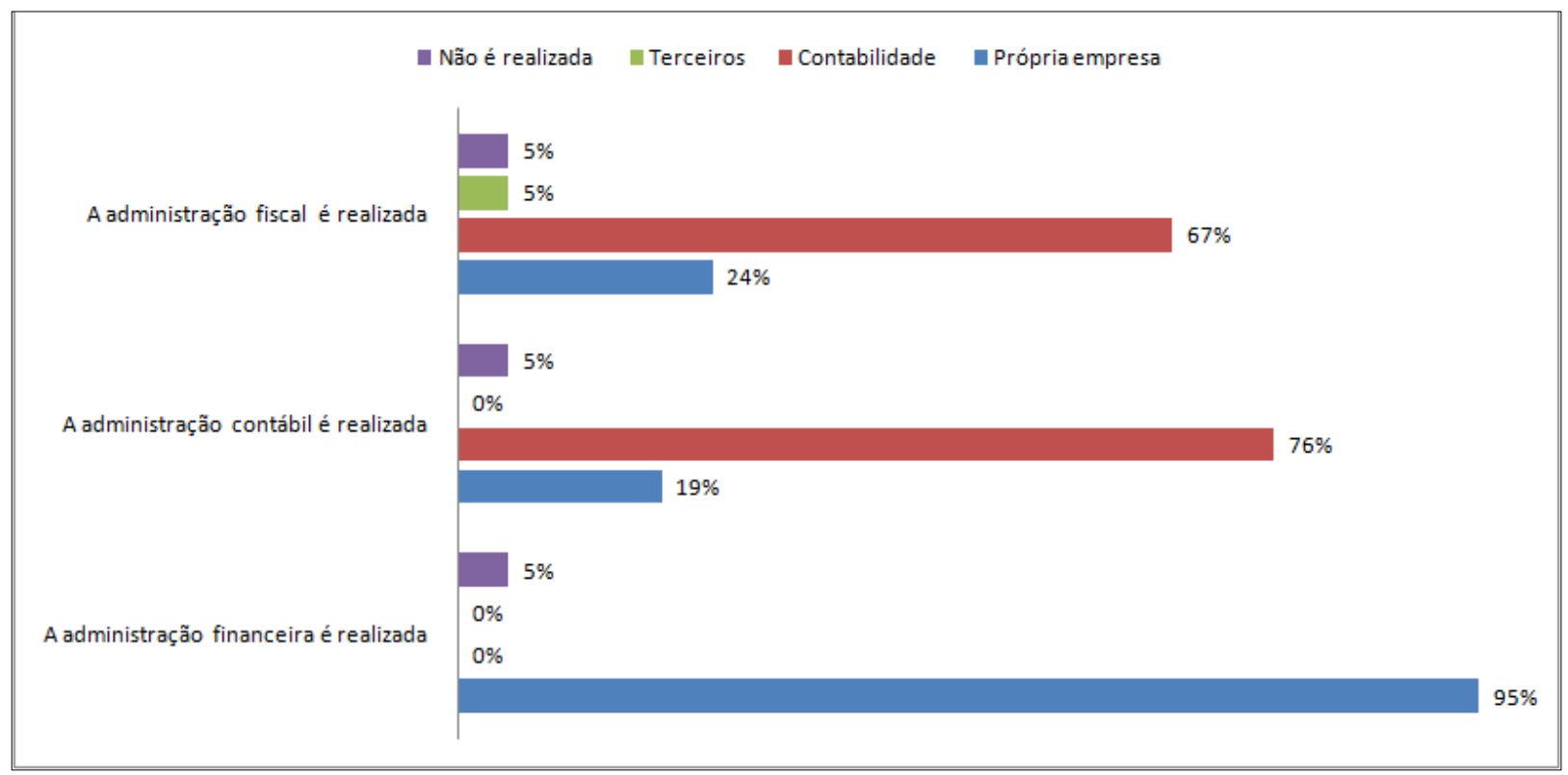

Gráfico 14 - Gestão Contábil, Fiscal e Financeira.

Fonte: Dados da Pesquisa.

L. Maior dificuldade enfrentada na Administração Financeira: De modo geral, os dados evidenciados na Tabela 16 e no Gráfico 15 demonstram que em $71 \%$ da amostra a maior dificuldade encontrada para Gestão Financeira é a elevada carga tributária. Outras dificuldades na Administração Financeira nas MEs e EPPs são: o aumento da concorrência (29\%), a falta de mão de obra qualificada (24\%) e as dificuldades para efetuar a correta gestão do Fluxo de Caixa (24\%). 


\begin{tabular}{l|c|c}
\hline Descrição & Frequência & $\%$ \\
\hline Alta carga tributária & 15 & $71 \%$ \\
\hline Concorrência acirrada & 6 & $29 \%$ \\
\hline Falta de mão de obra qualificada & 5 & $24 \%$ \\
\hline Dificuldades para gerir o fluxo de caixa & 5 & $24 \%$ \\
\hline Falta de recursos financeiros (dinheiro/crédito) & 4 & $19 \%$ \\
\hline Pouca experiência no setor de atuação & 3 & $14 \%$ \\
\hline Dificuldades para administrar custos e definir preços & 2 & $10 \%$ \\
\hline Falta de uma ferramenta de gestão e/ou de controles financeiros & 1 & $5 \%$ \\
\hline Falta de conhecimento & 1 & $5 \%$ \\
\hline
\end{tabular}

Tabela 16 - Avaliação Geral das Dificuldades da Gestão Financeira. Fonte: Dados da Pesquisa.

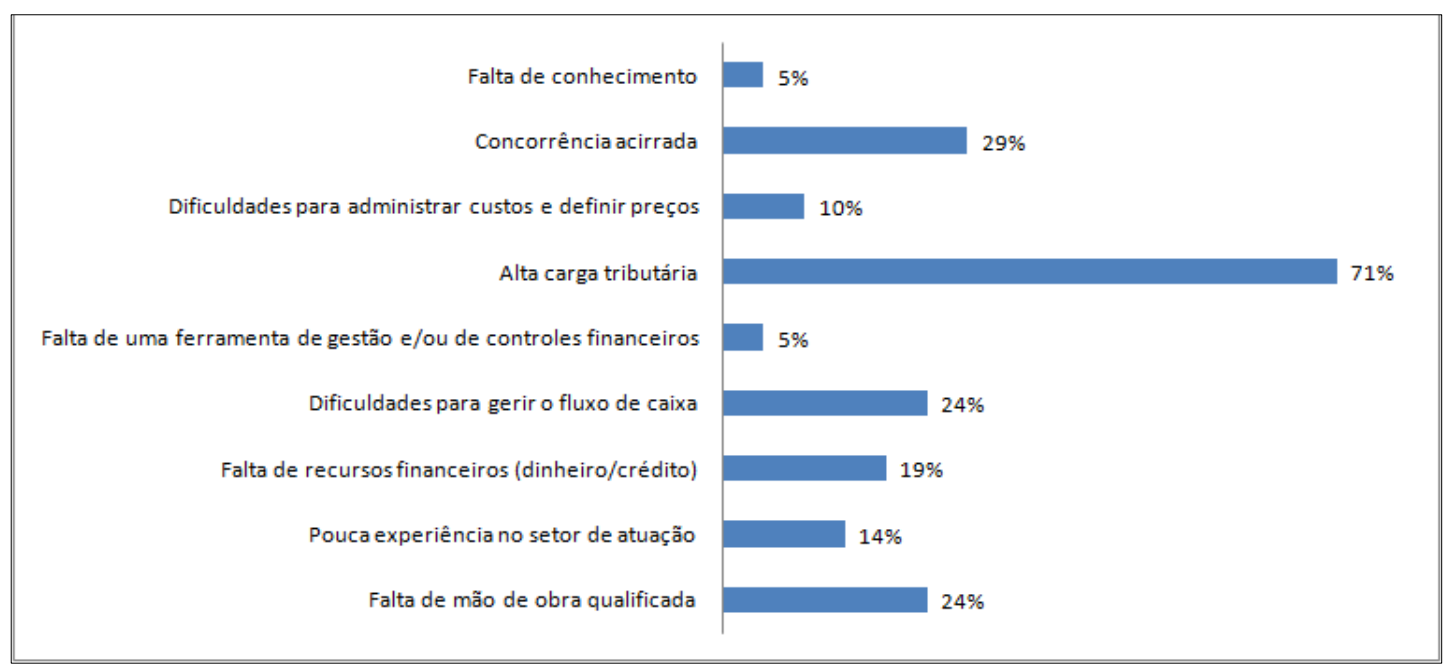

Gráfico 15 - Avaliação Geral das Dificuldades da Gestão Financeira.

Fonte: Dados da Pesquisa.

\section{5 - CONSIDERAÇÕES FINAIS}

A pesquisa revelou que $61,90 \%$ das MEs e das EPPs do município de Osasco são do setor de Comércio e Prestação de Serviços e, apesar de ter sido baseada em uma pequena amostra, não representativa, este dado está de acordo com o último estudo publicado pela Secretaria de Desenvolvimento, Trabalho e Inclusão de Osasco (SDTI) e pelo Departamento Intersindical de Estatística e Estudos Socioeconômicos (DIEESE) em agosto de 2011 chamado "Perfil das Micro e Pequenas Empresas no Município De Osasco" que informava que mais de $80 \%$ das MPEs do município são destes setores (Comércio e Prestação de Serviços). Com base neste dado, pode-se afirmar que o desenvolvimento e longevidade destas empresas são fundamentais para o desenvolvimento econômico do município de Osasco. Em 
relação ao perfil do responsável pela Gestão Financeira nas MPEs, nota-se que mais de 47\% possuem ensino superior completo, entretanto, 23,81\% possuem apenas o ensino médio ou ensino fundamental incompleto, o que pode impactar diretamente no modelo de gestão da empresa. Por exemplo, dentre as empresas que o gestor financeiro tem até o ensino médio $(23,81 \%)$, a única Demonstração Contábil elaborada é o Balanço Patrimonial, sendo que há casos onde nenhuma Demonstração Contábil é realizada. Vale ressaltar que mesmo nos casos onde o Balanço Patrimonial é realizado, este é feito por uma contabilidade terceirizada.

Este trabalho revela também que mais de $80 \%$ das MPEs dependem de uma contabilidade terceirizada para fazer a Gestão Contábil e Fiscal de suas empresas e que, apesar dos incentivos do governo e da criação do Simples Nacional, a maior dificuldade apontada para a Administração Financeira é a alta carga tributária. A falta de mão de obra qualificada também é apontada como uma das dificuldades enfrentadas na Administração Financeira das MPEs, o que pode ser explicado pelo fato da média de salários pagos nas MEs e EPPs serem, segundo a pesquisa "Perfil das Micro e Pequenas Empresas no Município de Osasco", menores do que os pagos pelas médias e grandes empresas.

Outro ponto importante observado neste trabalho é o fato de que $43 \%$ das empresas analisadas afirmaram que definem o preço de venda de suas mercadorias ou dos serviços oferecidos com base no mercado de atuação, o que pode ser uma das causas da baixa rentabilidade destas empresas, visto que para se determinar o preço de venda devem ser consideradas outras variáveis importantes, como o custo, por exemplo.

Vale ressaltar que, apesar de mais de $80 \%$ das empresas afirmarem realizar os controles financeiros básicos, estes controles são feitos, muitas vezes, de modo simplificado e sem grandes critérios, o que pode levar a erros de interpretação dos dados e consequentemente a perda de rentabilidade.

Um trabalho realizado no México intitulado "Un estudio comparativo del perfil financiero y administrativo de las pequeñas empresas en México: entidades del Estado de México, Hidalgo, Puebla, Sonora y Tamaulipas. Resultados finales escritos por pesquisadores de 5 universidades" encontrou resultados parecidos com os desta pesquisa, tais como: concorrência desleal, falta de capacitação de recursos humanos, problemas de gestão e administração, entre outros (CALZADA E AUBERT, 2015). O referido estudo ainda enfatiza que dentre as dificuldades que as PMEs encontram, destaca-se a falta de um Plano de 
Negócios, o que torna difícil obter financiamentos e coordenar de forma eficiente os recursos físicos e humanos, gerando uma operação mais difícil e atrasos em seu crescimento.

Para pesquisas futuras, sugere-se aplicar esta pesquisa a um número maior de MPEs para verificar se haverá alterações significativas nos resultados apresentados.

\section{REFERÊNCIAS}

BRASIL. Lei Complementar $n^{\circ} 123$, de 14 de dezembro de 2006. Institui o Estatuto Nacional da Microempresa e Empresa de Pequeno Porte

BRASIL. Lei $\mathrm{n}^{\circ}$ 10.406, de 10 de janeiro de 2002. Institui o Código Civil. Publicado em 10 de janeiro de 2002.

BRASIL. Constituição Federal - Código Comercial, Tributário Nacional, Processo Civil, Civil (Excertos) e Legislação Complementar. São Paulo, Manole, 2005.

CALZADA, H e AUBERT, M. Un estudio comparativo del perfil financiero y administrativo de las pequeñas empresas en México: entidades del Estado de México, Hidalgo, Puebla, Sonora y Tamaulipas. Resultados finales. Revista del Centro de Investigación. Universidad La Salle 2010, 9 (Enero-Junio). Disponível em: <http://www.uaeh.edu.mx/investigacion/producto.php?producto=3791>, acesso em 18 de mai. 2015.

CONSELHO FEDERAL DE CONTABILIDADE. Resolução CFC $\mathrm{n}^{\circ} 1.418$, de 05 de dezembro 2012. Aprova a ITG 1000-Modelo Contábil para Microempresa e Empresa de Pequeno Porte. Brasília - DF. Disponível em: <http://www2.cfc.org.br/sisweb/sre/detalhes_sre.aspx?Codigo= 2012/001418>, acesso em 20 out. 2014.

DIEESE (Departamento Intersindical de Estatística e Estudos Socioeconômicos) e OBSERVATÓRIO DO TRABALHO E OSASCO. Estudo Temático II: Micro e Pequenas Empresas e Microempreendedor Individual no município de Osasco. DIEESE: Osasco, julho/2014. Disponível em: <http://geo.dieese.org.br/osasco/download.php?ce=361>, acesso em 20 out. 2014.

DIEESE (Departamento Intersindical de Estatística e Estudos Socioeconômicos) e OBSERVATÓRIO DO TRABALHO E OSASCO. Perfil Das Micro E Pequenas Empresas No Município De Osasco. DIEESE: Osasco, agosto/2011. Disponível em: <http://geo.dieese.org.br/osasco/download.php?ce=244>, acesso em 20 out. 2014.

GITMAN, L. J. Princípios de Administração Financeira: 12. ed. São Paulo: Pearson, 2012. 
SANTOS, F. A. e VEIGA, W. E. Contabilidade: com Ênfase em Micro, Pequenas e Médias Empresas. São Paulo: Atlas, 2014.

SEBRAE MG - Serviço de Apoio às Micro e Pequenas Empresas de Minas Gerais. (s.d.). Disponível em: <www.sebraemg.com.br>, acesso em 10 out. 2014.

SEBRAE SP - Serviço de Apoio às Micro e Pequenas Empresas de São Paulo. (s.d.). Disponível em: <http://www.sebraesp.com.br/>, acesso em 10 de out. de 2014.

TEIXEIRA, K. (2012). Controles Financeiros em Micro, Pequenas e Médias Empresas. In: BARROS NETO, J. P. e SOUZA, G. Manual do Empreendedor de Micro e Pequenas Empresas. Rio de Janeiro: Qualitymark, 2011. p. 335-350. 